\title{
IPA NEWS
}

\section{FUNDING FOR STUDENT MEMBERS TO ATTEND ICPhS}

The Association will offer two kinds of travel awards to student members presenting their work at the International Congress of Phonetic Sciences in August 2015. Gösta Bruce Scholarships are funded by the Gösta Bruce Memorial Fund, established by the family of the late Gösta Bruce, previous President of the IPA. IPA Student Awards are funded by the Association. The deadline for applications for both kinds of awards will be in late May. Information about the numbers and amounts of the awards, and about the application procedures, is available on the IPA website under 'Grants'.

The Gösta Bruce Memorial Fund depends on continuing donations. IPA members are asked to consider contributing to the Fund in order to increase the number of Gösta Bruce Scholarships that can be awarded to students in 2015. Information about how to contribute to the Fund is on the IPA website under 'Grants - How to contribute to the Fund'.

\section{Patricia A. Keating}

Secretary

Journal of the International Phonetic Association (2015) 45/1 doi:10.1017/S0025100314000486

(C) International Phonetic Association

\section{CERTIFICATE EXAMS 2015}

The IPA certificate exam will be offered in connection with ICPhS in Glasgow, on Sunday 9 August 2015. It will also be offered in London (at UCL) twice, on Wednesday 20 May 2015 and Tuesday 1 September 2015. (All offerings are subject to confirmation, requiring a sufficient number of entrants.)

The regular exam fee will be $£ 75$ for all 2015 offerings of the exam. Student members of the IPA will receive a $50 \%$ discount on this fee.

The Glasgow offering of the exam requires registration two months in advance, while the London offerings require registration one month in advance. See http://www. internationalphoneticassociation.org/ for registration and other information.

\section{Patricia A. Keating}

Secretary 